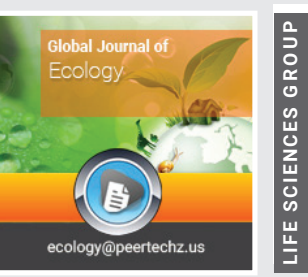

Review Article

\section{Contribution to the identification of morphological descriptors for the genetic diversity of argan tree (Argania spinosa L. Skeels)}

\author{
Alfred Balenor Buernor ${ }^{1 *}$, Ahmed Amri' ${ }^{2}$, Ahmed Birouk ${ }^{3}$, \\ Chafik Analy ${ }^{1}$, Zakaria Kehel ${ }^{4}$ and Abderrahmane Aitlhaj ${ }^{5}$ \\ ${ }^{1} \mathrm{MSc}$, Graduate, Agronomy, and plant Genetics, InstitutAgronomique et Vétérinaire Hassan II, Rabat, \\ Morocco \\ ${ }^{2} \mathrm{PhD}$, Graduate, Head of genetic resources, International Center for Agriculture Research in Dry Areas \\ Rabat, Morocco \\ ${ }^{3}$ Professor, Department of plant protection and biodiversity, Institut Agronomique et Vétérinaire \\ Hassan II, Rabat, Morocco \\ ${ }^{4} \mathrm{PhD}$, Graduate, International Center for Agriculture Research in Dry Areas, Rabat, Morocco \\ ${ }^{5}$ National Agency for the Development of Oases Areas and Argan Zones (ANDZOA), Agadir, Morocco
}

Received: 26 May, 2021

Accepted: 11 June, 2021

Published: 12 June, 2021

*Corresponding author: Alfred Balenor Buernor, MSc Graduate, Agronomy, and plant Genetics, InstitutAgronomique et Vétérinaire Hassan II, Rabat, Morocco, E-mail: abbalenor@gmail.com

Keywords: Argania spinosa; Morphological characterization; Descriptors; Genetic diversity; Conservation

https://www.peertechzpublications.com

Check for updates

\title{
Abstract
}

The argan tree (Argania spinosa L. Skeels) is a species of great ecologic, economic and social importance in Morocco. It is a multi-purpose tree supporting the livelihoods of rural communities in the south-west parts of the country with increasing interest in using its oil in cosmetics and pharmaceutical industries. The anthropological overuse combined with parasitic attack and recurrent droughts contribute to the rapid degradation of its ecosystem. The efficient in situ conservation of the argan tree and its ecosystem as well as breeding efforts for the domestication of this species require the development of descriptors for the characterization of the diversity and identification of the argan tree. This work aims to contribute to the identification of key descriptors of the argan tree using qualitative characteristics related to tree shapes, twigs, leaves, fruits, and seed as well as quantitative measures of these same organs. A total of 255 trees were sampled at four sites in four provinces, namely: Agadir, Essaouira, Sidi Ifni and Ait Baha. A total of thirty-one characteristics were assessed. The results showed a high morphological diversity for many of both qualitative and quantitative characteristics at all sites. However, the frequencies of the different classes and the share of variance for each trait vary across sites. The qualitative characteristics were more discriminant especially the shape of the fruit, the shape of the leaves, the leaf surface, the shape of the tree and the colour of the leaves are very variable and have a strong contribution to explanation of the diversity of the argan tree. The leaf area, seed area, number of carpels, density of spines, and branch length explain nearly $42 \%$ of the diversity and can serve as descriptors of argan tree diversity which can help in the efficient conservation of the argan ecosystem and in the selection and protection of clones for the promotion of arganiculture.

\section{Introduction}

Argania spinosa (L.) Skeels, the only species of the tropical family of Sapotaceae in Morocco, is widespread in the arid and semi-arid regions of southwest Morocco [1]. The argan tree plays an essential role in ecological balance and in the preservation of the biodiversity of the region due to its powerful root system which contributes to soil maintenance and helps to fight against water and wind erosion which prevent further land degradation and desertification. It has an undeniable ecological and economic value supporting the livelihoods of local communities living under harsh and dry conditions. The argan tree is of great economic interest thanks to its multiple uses. Each part of the tree is useful and provides a source of income or food for the users. Its wood is used as fuel, leaves and fruits are fodder for goats and camels, and the oil extracted from its almond is used for human consumption, cosmetics and traditional medicine [2]. As a result, the argan tree is considered 
as a national resource with a high ecological and socio-economic impact. But the argan ecosystem is undergoing an alarming degradation due to anthropogenic factors combined with the effects of climate change and parasitic attack. Almost half of the argan grove has disappeared and its average density has decreased from 100 to 30 trees/ha [3]. The in-situ conservation and sustainable use of the argan ecosystem requires a better characterization of the diversity of the argan tree through the development of descriptors specific to this species. The argan (Argania spinosa L. Skeels) is a multi-purpose tree which supports the livelihoods of rural communities in the drylands of Morocco. However, the anthropological overuse combined with parasitic attack and recurrent droughts contribute to the rapid degradation of its ecosystem. Seeking descriptors of argan tree diversity for conservation of the argan ecosystem and promotion of arganiculture is valuable.

These descriptors should allow an easy and quick distinction between the different accessions and are most often based on qualitative phenotypic characteristics, preferably judged using internationally adopted measures and scales. The development of descriptors for a large number of species and crops of global importance in agriculture and food was coordinated by Bioversity International and its predecessors (the International Board for Plant Genetic Resources (IBPGR) and the International Plant Genetic Resources Institute (IPGRI)) with a large number of national and international specialists. However, descriptors for forest trees are only developed for a few species. Limited studies have been done on argan tree.

The form of the argan tree (Argania spinosa L. Skeels) has two different classifications. For some, there are two types: the spinely upright type and the spineless drooping type. For others, there are five morphological types. These five morphological types were described by Zahidi in 1995 [4]. Later, an elaborated characterization was done on the basis of twenty-one branching and growth characteristics by Zahidi, et al. [5]. who identified, Type I; very thorny and very branched tree with very short branches, Type II; thorny, branched with short branches, Type III; very thorny, very branched with moderately long branches, Type IV; thorny, less branched with long branches and lastely the, Type V; very little thorns, slightly branched with very long branches. Bani-Aameur [6] identified four morphological forms of the leaf in four main ecosystems of the argan tree's range in southwest Morocco (obovate obtuse, lanceolate acute, lanceolate mucronate and spatulate obtuse). Other researchers focused on the morphometric characterization of leaves [1,7]. Metougui, et al. [7]. studied two characteristics of a year old twig (length and spine density), Bani-Aameur, et al. [8] described five fruit shapes (fusiform, oval, ellipsoid, narrowly ellipsoid and rounded) and three seed shapes (fusiform, oval and rounded)[9-11].

This study is part of a national perspective for the conservation and sustainable use of argan ecosystems in Morocco to ensure rural development of local populations. The main objectives are $i$ ) Characterization of the argan tree diversity based on morphological characteristics $i$ ) Contribution to the identification of key descriptors of the argan tree which could possibly be use in describing selected clones to promote arganiculture.

\section{Material and methods}

\section{Study zone}

In the context of this study, surveys and collections were carried out in four provinces among the five main provinces of the argan forest (namely Agadir, Essaouira, Ait Baha, and Sidi Ifni) through the selection of pilot sites belonging to different eco-geographical situations. The selected sites are covering the gradients west (Agadir) to east (Ait-Baha) and north (Essaouira) to south (Sidi Ifni) covering regions with ariddesertic to arid with Atlantic and altitude influence Figure 1.

\section{Plant material}

In order to have a representative sample of the argan tree population, a total of 255 trees were sampled in the 4 provinces, of which 80 trees were sampled at Mesguina (Agadir), 51 trees at Khmiss de Touighza (Sidi Ifni province), 60 trees at Ait Baha and 64 trees at Tafedna (Essaouira province). In each province, trees are selected from five quadrats (size of $40 \mathrm{mx} 40 \mathrm{~m}$ each) along each transect covering the diversity of altitude and the exposition. Two transects for the province of Agadir and one transect for each of the other three sites were chosen. In each quadrat, 4 to 6 trees were chosen on the basis of apparent phenotypic diversity (shape of the tree and branches, leaf color, fruit shape). In addition, some trees were randomly sampled outside the quadrats but within the same sites for a better characterization of the genetic diversity. Adult, vigorous and healthy trees were selected. The GPS coordinates of the quadrats and those of each selected tree were recorded. The measured tree traits are listed in Table 1.

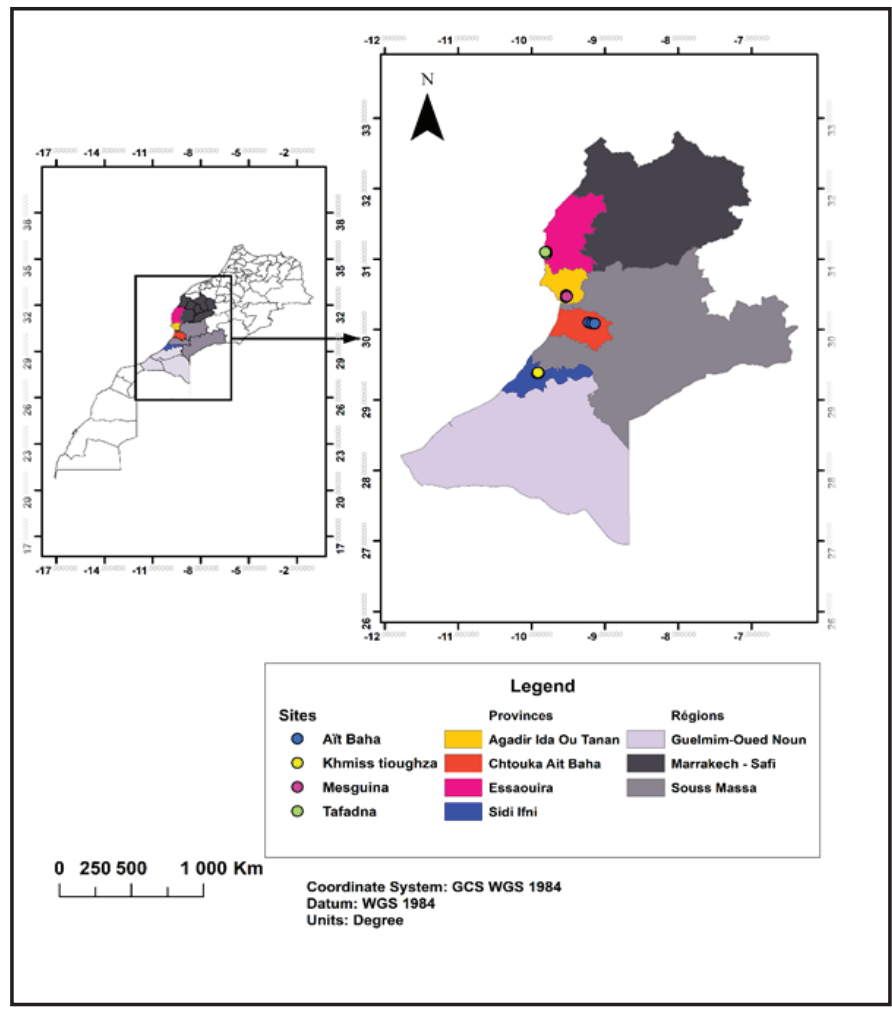

Figure 1: Localization of the Argan tree surveyed areas within the administrative map of the study zone. 
Table 1: List of characters used for the characterization of the argan trees, with their units, the size of the sample and the measurement method (Abr; $A b b r e v i a t i o n s, ~ N R G$; number of repetitions).

\begin{tabular}{|c|c|c|c|c|}
\hline Organ & Characters & Abr. & NRG & Measurement and estimation methods \\
\hline \multirow{8}{*}{ Tree trunk } & Height (m) & $\mathrm{TH}$ & & Cross- lumberjack method [9]. \\
\hline & Diameter (m) & TD & & Taken at $1.5 \mathrm{~m}$ from the ground level [9] \\
\hline & Average cover diameter(m) & TC & & Estimated through the projection on the ground \\
\hline & Growth habit & TGh & & As described by UPOV [10] \\
\hline & Form & TF & & As described by Zahidi et al. [5] \\
\hline & Health status & Thl & & Good, average, bad base on the level of attack \\
\hline & Growth stage & TGs & & Adult, juvenile or seedling \\
\hline & Number of trunks & NT & & Visual count of number of trunks \\
\hline \multirow{4}{*}{ Branch } & Internode distance (mm) & $\ln \mathrm{D}$ & 2 & \multirow{3}{*}{ Length of a year-old branch measured with the help of a tape measure } \\
\hline & Length $(\mathrm{cm})$ & $\mathrm{BrL}$ & 2 & \\
\hline & Spine length (mm) & SpL & 2 & \\
\hline & Spine density & $\mathrm{SpD}$ & 2 & Number of spines on $20 \mathrm{~cm}$ of a branch of 2 years old \\
\hline \multirow{8}{*}{ Leaf } & Length (mm) & LfL & \multirow{8}{*}{5} & \multirow{4}{*}{ Through grain scan as illustrated and described in Description of leaves below. } \\
\hline & Width (mm) & LfW & & \\
\hline & Perimeter $(\mathrm{mm})$ & LfP & & \\
\hline & Surface area $\left(\mathrm{mm}^{2}\right)$ & LfA & & \\
\hline & Color & LfC & & Predominant color of adult leaves on the whole tree \\
\hline & Form & LfF & & \multirow{3}{*}{ Based on How to identify Australian Native Tree Species by Leaf Characteristic [11] } \\
\hline & Form of apex & $\mathrm{LaF}$ & & \\
\hline & Form of base & LbF & & \\
\hline \multirow{4}{*}{ Fruit } & Length $(\mathrm{cm})$ & FrL & 10 & \multirow{2}{*}{$\begin{array}{l}\text { Taken from the farthest ends of length and diameter respectively with a digital caliper (precision of } \\
\qquad 0.02 \mathrm{~mm} \text { ) }\end{array}$} \\
\hline & Diameter $(\mathrm{cm})$ & FrD & 10 & \\
\hline & Length/diameter ratio & FrR & 10 & length of fruit divided by its diameter \\
\hline & Form & $\mathrm{FrF}$ & 10 & Based on the work of Bani-Aameur et al. [8] \\
\hline \multirow{7}{*}{ Seed } & Length (mm) & SdL & 10 & \multirow{4}{*}{ With a grain scan } \\
\hline & Diameter (mm) & SdD & 10 & \\
\hline & Surface area $\left(\mathrm{mm}^{2}\right)$ & SdA & 10 & \\
\hline & Perimeter $(\mathrm{mm})$ & SdP & 10 & \\
\hline & Weigth of 10 grains $(\mathrm{g})$ & SdW & 10 & Precision balance. \\
\hline & Number of carpels & $\mathrm{SnC}$ & 10 & The number of visible endocarps counted manually \\
\hline & Form & SdF & 10 & Based on the work of Bani-Aameur et al. [8] \\
\hline
\end{tabular}

\section{Estimation of leaf dimensions}

The argan tree has two types of leaves: simple alternate leaves that grow on the branch of the year and grouped leaves which grow on the ligneous branches. This study only concerns simple leaves because they are more uniform within a given tree [12]. On the other hand, on the same tree, two to five different shapes can be found from the grouped leaves.

For each tree, 10 fully developed, predominant simple leaves were collected from the twig of the year. The quantitative characters studied are: length, width, perimeter and surface area (Table 2). The sampled leaves were photographed on a calibrated $\left(1 \mathrm{~cm}^{2}\right)$ support fixed at the constant distance (about $7 \mathrm{~cm}$ ) between the support and the camera (a tablet) (Figure 2). The photos were then printed on an $\mathrm{A}_{4}$ paper, and five representative leaves were cut out as well as two reference squares: one from the scale of the photo (the large square in Figure 2) and another of $1 \mathrm{~cm}^{2}$. The leaves and the scales are scanned in using a CanoScan LiDE 220 scanner (Image 1). The photos of the first scan (image 1) were processed with CSIRO GrainScan which gave the leaf dimensions. The two squares were used for the conversion between the scan data and the true leave size using the principle of proportionality [13]. Since we know the true size of the large square $(1 \times 1 \mathrm{~cm})$ before taking the picture, the size of this square after the scan and that of the leaves given by the scan. The second small square of $1 \mathrm{x} 1 \mathrm{~cm}$ is
Table 2: Results of ANOVA for analysis of differences between regions of various characteristics of Argan tree.

\begin{tabular}{|l|l|l|l|l|l|}
\hline $\begin{array}{l}\text { Source of } \\
\text { variation }\end{array}$ & Df & Sum of Sq & Wald statistic & $\operatorname{Pr}$ (Chisq) & Trait \\
\hline Region & 3 & 2274.2 & 473.3 & 0 & $\begin{array}{l}\text { Trees height } \\
\text { Crown } \\
\text { diameter }\end{array}$ \\
\hline Region & 3 & 1394.7 & 122.3 & 0 & Leaf area \\
\hline Region & 3 & 924182.1 & 203.9 & 0 & Leaf perimeter \\
\hline Region & 3 & 99321.5 & 218.2 & 0 & Leaf length \\
\hline Region & 3 & 4916.2 & 86.6 & 0 & Leaf width \\
\hline Region & 3 & 916.1 & 157.5 & 0 & Fruit length \\
\hline Region & 3 & 88.0 & 119.6 & 0 & Fruit diameter \\
\hline Region & 3 & 30.2 & 105.3 & 0 & Fruit L/D ratio \\
\hline Region & 3 & 20.6 & 109.5 & 0 & Seed area \\
\hline Region & 3 & 186391.0 & 30.3 & $1.21 \mathrm{E}-06$ & Seed perimeter \\
\hline Region & 3 & 12787.5 & 29.8 & $1.56 \mathrm{E}-06$ & Seed length \\
\hline Region & 3 & 2193.4 & 57.9 & $1.67 \mathrm{E}-12$ & $\begin{array}{l}\text { Diameter of } \\
\text { stem }\end{array}$ \\
\hline Region & 3 & 256538.1 & 415.5 & 0 & Seed width \\
\hline Region & 3 & 302.5 & 19.7 & 0.000192491 & IND \\
\hline Region & 3 & 107.4 & 19.1 & 0.000258929 & $\begin{array}{l}\text { Number of } \\
\text { trunks }\end{array}$ \\
\hline Region & 3 & 3440.9 & 389.1 & 0 & Number of \\
carpels
\end{tabular}


a kind of control to check the results of the scan but the latter was used in the calculations for more precision.

\section{Statistical analyses}

The data was evaluated for outliers using boxplot boxes. Outliers were then removed by considering them as missing values. Summary descriptive statistics including means and standard deviations were calculated for all numeric characters. Frequency tables were also prepared to summarize the qualitative traits. The analysis of variance components was performed for all numerical characteristics using the data collected for all trees and using a mixed linear model. Provinces, transects in provinces and trees in transects were considered random. Another analysis of variance components to measure variability by province was also conducted. The analysis of the mixed models was performed using the R (R Core Team 2016) lme4 library [14].

To identify the key descriptors for argan tree, two methods were used: i) Analysis of variance of all the studied traits. The importance of a variable for discriminating trees is then given by the average sum of the squares and by the statistical $\mathrm{F}$ value. ii) Multiple regression model for selection using an exhaustive stepwise regression. This is done by adding a new variable each time, deleting it and checking the change in the $\mathrm{R}$ squared. The best model is then selected based on Akaike's information criteria, AIC [15]. This was done using the R-leap package [16].

To elucidate the difference in climate of the four regions and their possible effect on phenotypic traits, we did an analysis of variance between regions and used the GPS coordinates of each sampled tree to extract bioclimatic data from worldclim2 database [17] (https://www.worldclim.org/data/bioclim.html) at 2.5 minutes spatial resolution. The data was standardized and PCA was performed using the Factoextra and FactoMiner $\mathrm{R}$ packages. The eigenvalues and trees distribution were mapped in the PC1 x PC2 plan.

\section{Results}

The tree height and all the other twenty quantitative traits were significantly different between the study sites (Table 2). The results of the principal component analysis of the bioclimatic data of the study zone showed that each region belongs to a distinct agroecological zone (Figure 3). The first two PCAs explained more than $94 \%$ of total variance of climate conditions in the study zones.

\section{Quantitative characteristics}

Tree characteristics: The general average tree height for the total sample is $7.33 \mathrm{~m}$ with those of Ait Baha $(8.45 \mathrm{~m})$ and Agadir $(7.99 \mathrm{~m})$ slightly above the overall average and are on average taller than those from Essaouira and Sidi Ifni sites (Table 3). The crown diameter is larger on average in Essaouira $(12,08 \mathrm{~m})$ and its maximum is $14 \mathrm{~m}$ at Sidi Ifni. The Essaouira site showed the highest average (5.6) and maximum number of trunks (17) per tree followed by Ait Baha. For the branch length, high variability exists in all sites with the greatest amplitude shown at Agadir. Similarly, the internodes distance

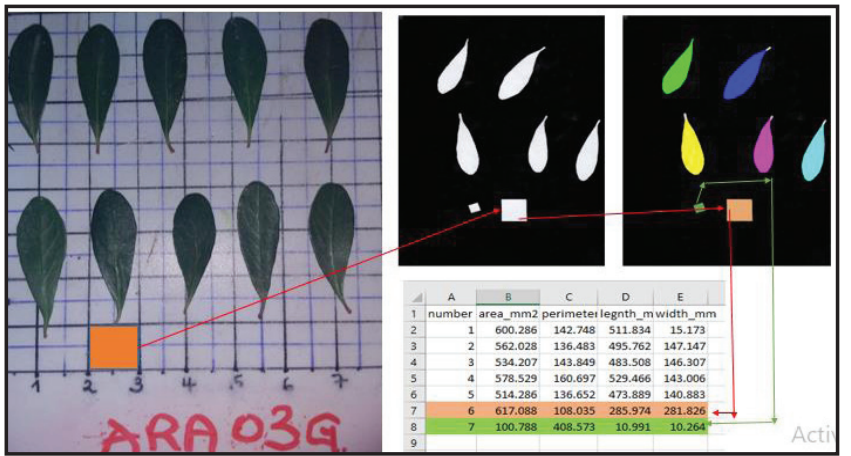

Figure 2: Images of argan tree leaves, two squares and their corresponding values (the large square: photo scale and the smaller one is $1 \mathrm{~cm}^{2}$ cut and scanned with a CanoScan LiDE 220 (white and black) and CSIROGrainScan (colour) scanner grain.

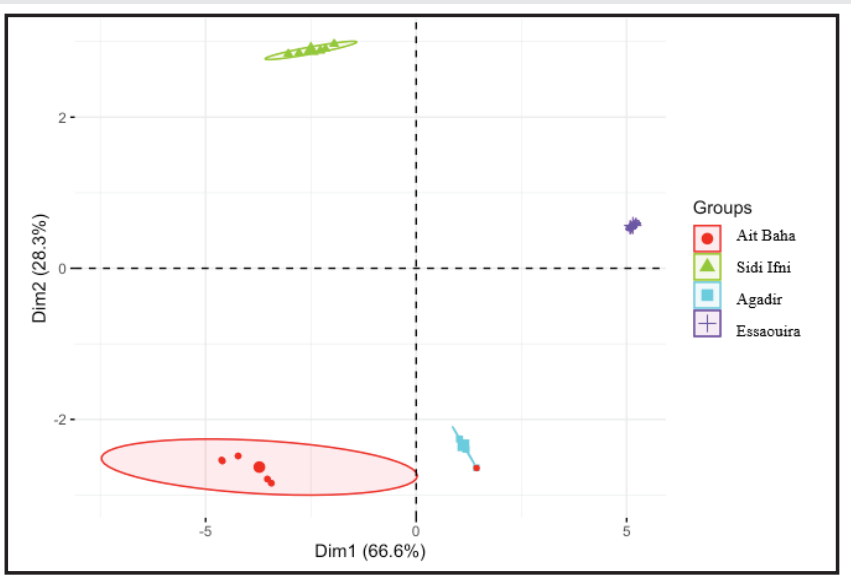

Figure 3: Two-dimensional PCA plot based on the two first components of bioclimatic data of the four regions surveyed for argan tree diversity.

showed high variability within each site with no differences between sites averages ( 8.40 to $8.97 \mathrm{~mm})$. The spineless twigs of a year old are present in very few individuals at each site. The average spine length is approximately $1 \mathrm{~cm}$ at all the sites.

\section{Leaf characteristics}

On average, the leaf area is $180.29 \mathrm{~mm} 2$, the perimeter 99.72 $\mathrm{mm}$, the length $26.87 \mathrm{~mm}$ and the width $8.68 \mathrm{~mm}$ (Table 3) with respective maximums of $457.61 \mathrm{~mm} 2$ in Essaouira, 147.0 $\mathrm{mm}$ in Sidi Ifni, $58.66 \mathrm{~mm}$ in Sidi Ifni and 16.82 in Ait Baha. However, large variations for all this dimensions are observed in each of the four sites, with the greatest amplitudes found in Agadir for the leaf surface and leaf perimeter, in Ait Baha and Sidi Ifni for the leaf length and in Essaouira for the leaf width.

\section{Fruit and seed characteristics}

Large variations were observed for length, diameter as well as for the diameter/length ratio of the fruits both on the total samples and within each site. However, the averages between the sites remains less variable. The maximum fruit length and diameter of $5 \mathrm{~cm}$ and $3.68 \mathrm{~cm}$ respectively were observed in Essaouira. For the seeds, the most variable traits are the surface area $\left(206.67 \pm 60.92 \mathrm{~mm}^{2}\right)$ and the perimeter $(69.52 \pm 11.37 \mathrm{~mm})$. In general, Agadir trees showed the highest values for these characteristics. Similarly, the weight of 10 seeds showed high variability within each site with an amplitude ranging from 5 
Table 3: Descriptive statistics ( $\overline{\mathrm{y}}$ : average, $\bar{\delta}$ : standard deviation) of the quantitative characteristics of the argan trees by site and all sites.

\begin{tabular}{|c|c|c|c|c|c|c|}
\hline Characteristics & Mean and Standard deviation & Agadir & Ait Baha & Esssaouira & Sidi Ifni & General Total \\
\hline \multirow{2}{*}{ Tree Height (m) } & $\bar{y}$ & 7.99 & 8.45 & 5.59 & 6.19 & 7.33 \\
\hline & $\delta$ & 2.44 & 2.58 & 1.76 & 1.91 & 2.54 \\
\hline \multirow{2}{*}{ Crown diameter $(\mathrm{m})$} & $\bar{y}$ & 10.76 & 10.25 & 12.08 & 9.29 & 10.64 \\
\hline & $\delta$ & 3.98 & 4.22 & 3.52 & 3.36 & 3.98 \\
\hline \multirow{2}{*}{ Number of trunks } & $\bar{y}$ & 2.78 & 3.19 & 5.60 & 2.45 & 3.47 \\
\hline & $\delta$ & 2.31 & 3.11 & 3.79 & 2.62 & 3.21 \\
\hline \multirow{2}{*}{ Branch length $(\mathrm{cm})$} & $\bar{y}$ & 23.59 & 24.46 & 20.58 & 20.40 & 22.44 \\
\hline & $\delta$ & 10.47 & 8.55 & 8.71 & 7.48 & 9.20 \\
\hline \multirow{2}{*}{ Internode distance (mm) } & $\bar{y}$ & 8.47 & 8.97 & 8.75 & 8.40 & 8.65 \\
\hline & $\delta$ & 2.54 & 2.45 & 2.48 & 1.93 & 2.41 \\
\hline \multirow{2}{*}{ Spine density } & $\bar{y}$ & 16.57 & 15.77 & 19.61 & 18.6 & 17.51 \\
\hline & $\delta$ & 8.33 & 8.86 & 6.86 & 9.16 & 8.43 \\
\hline \multirow{2}{*}{ Spine length (mm) } & $\bar{y}$ & 1.00 & 1.05 & 1.02 & 1.04 & 1.03 \\
\hline & $\delta$ & 0.20 & 0.20 & 0.13 & 0.13 & 0.16 \\
\hline \multirow{2}{*}{ Leaf area $\left(\mathrm{mm}^{2}\right)$} & $\bar{y}$ & 145.35 & 166.70 & 207.71 & 214.66 & 180.29 \\
\hline & $\delta$ & 68.34 & 64.47 & 67.11 & 69.39 & 73.25 \\
\hline \multirow{2}{*}{ Leaf perimeter (mm) } & $\bar{y}$ & 80.00 & 100.00 & 103.75 & 113.33 & 99.72 \\
\hline & $\delta$ & 29.96 & 14.18 & 20.92 & 18.24 & 24.36 \\
\hline \multirow{2}{*}{ Leaf length (mm) } & $\bar{y}$ & 23.87 & 27.79 & 27.40 & 29.55 & 26.87 \\
\hline & $\delta$ & 6.03 & 9.70 & 6.25 & 7.98 & 7.82 \\
\hline \multirow{2}{*}{ Leaf width $(\mathrm{mm})$} & $\bar{y}$ & 7.74 & 8.00 & 9.79 & 9.55 & 8.68 \\
\hline & $\delta$ & 2.49 & 2.49 & 2.11 & 2.54 & 2.58 \\
\hline \multirow{2}{*}{ Fruit length(cm) } & $\bar{y}$ & 2.68 & 3.05 & 2.69 & 2.67 & 2.78 \\
\hline & $\delta$ & 0.56 & 0.54 & 0.64 & 0.50 & 0.58 \\
\hline \multirow{2}{*}{ Fruit diameter $(\mathrm{cm})$} & $\bar{y}$ & 1.81 & 1.93 & 1.93 & 1.99 & 1.91 \\
\hline & $\delta$ & 0.32 & 0.24 & 0.35 & 0.25 & 0.30 \\
\hline \multirow{2}{*}{ Fruit ratio length/diameter } & $\bar{y}$ & 1.50 & 1.59 & 1.40 & 1.35 & 1.47 \\
\hline & $\delta$ & 0.28 & 0.29 & 0.24 & 0.21 & 0.28 \\
\hline \multirow{2}{*}{ Seed weight (g) } & $\bar{y}$ & 19.57 & 20.97 & 19.72 & 18.51 & 19.74 \\
\hline & $\delta$ & 8.01 & 6.83 & 8.78 & 6.76 & 7.65 \\
\hline \multirow{2}{*}{ Seed surface area $\left(\mathrm{mm}^{2}\right)$} & $\bar{y}$ & 204.28 & 212.07 & 227.34 & 185.71 & 206.67 \\
\hline & $\delta$ & 61.72 & 54.82 & 69.92 & 51.40 & 60.92 \\
\hline \multirow{2}{*}{ Seed perimeter $(\mathrm{mm})$} & $\bar{y}$ & 70.47 & 71.86 & 70.93 & 64.33 & 69.52 \\
\hline & $\delta$ & 11.65 & 10.04 & 13.14 & 9.19 & 11.37 \\
\hline \multirow{2}{*}{ Seed length (mm) } & $\bar{y}$ & 19.58 & 20.82 & 20.14 & 17.77 & 19.62 \\
\hline & $\delta$ & 3.67 & 3.81 & 4.14 & 3.11 & 3.85 \\
\hline \multirow{2}{*}{ Seed diameter $(\mathrm{mm})$} & $\bar{y}$ & 13.15 & 12.91 & 14.15 & 13.17 & 13.28 \\
\hline & $\delta$ & 2.32 & 1.74 & 2.11 & 1.83 & 2.06 \\
\hline \multirow{2}{*}{ Number of carpels } & $\bar{y}$ & 2.20 & 2.07 & 2.27 & 2.23 & 2.20 \\
\hline & $\delta$ & 0.93 & 0.50 & 1.04 & 0.67 & 0.83 \\
\hline
\end{tabular}

to $49.4 \mathrm{~g}$ for the total samples but the averages per site are similar. For the number of carpels per seed, it varied from 2 to 4 for the provinces of Agadir and Essaouira and from 2 to 3 for the other two provinces. No tree sampled showed a single carpel or more than four carpels per seed.

\section{Qualitative characteristics}

Characteristics of the tree: Three forms of growth habits of the argan tree were observed at all the four sites surveyed (Figure 4). At Sidi Ifni, there was a predominance of upright trees accounting for $58 \%$, followed by the spreading form accounting for $38 \%$ and finally $4 \%$ of the drooping forms (Figure 5). Among the 255 trees, the drooping shape is rare and only represents $7 \%$, the upright shape represents $58 \%$ and those with spreading growth habit are around 35\% (Table 5). In all the surveyed sites, there are at least two drooping trees among the samples.

\section{Leaf characteristics}

Apart from round leaves, which are rare and only found in the provinces of Agadir, Essaouira and Sidi Ifni, all other leaf shapes are represented in all four provinces (Figure 6). The oblanceolate form is the most dominant (29\%) followed by the lanceolate $(27 \%)$, elliptic $(20 \%)$, obovate $(15 \%)$ oval $(7 \%)$ and finally, the round form ( $2 \%$ ) (Table 5 ). The two main forms of the leaf blade apex are the acute/attenuated and round forms, which represent 34 and $65 \%$ for the total samples, respectively. These two forms are found in all the four provinces (Table 5). On the other hand, the notched shape is only found in the province of Essaouira and on only two trees. The two main leaf base forms observed are the wedge-shaped form and the attenuated form which represent 46 and $49 \%$ respectively of the total number of samples. The obtuse shape is possessed by only about $5 \%$ of the sampled trees (Table 5 ).

Four main simple leaf colours were observed viz. green, 


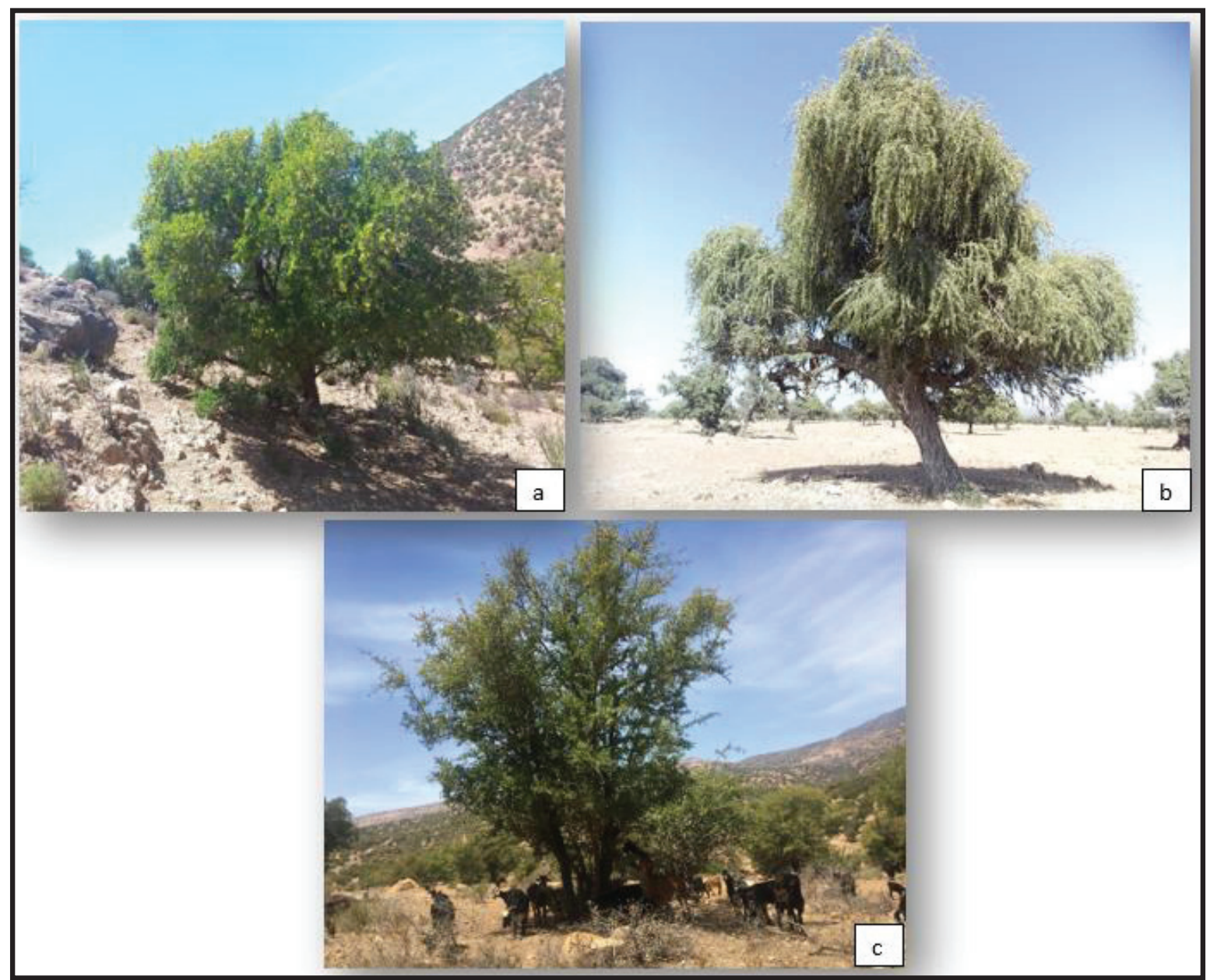

Figure 4: Argan trees with different growth habit (a) spreading form (b) drooping and (c) upright form in their natural habitat in Agadir.

yellowish green, Dark green and light green. The green color is the most dominant in all the sites except in Agadir where the yellowish green color predominates. The total representation of simple leaf colour in all the regions combined is 39\%, 30\%, $20 \%$ and $11 \%$ for green, yellowish green, dark green and light green respectively (Table 5).

\section{Characteristics of fruits and seeds}

In terms of fruit shape/form, all provinces are diversified. The ellipsoidal form characterized at least one-third of the samples in each province (Figure 7). The argan population is composed of $27 \%$ trees with obovate fruit, $32 \%$ ellipsoids, $9 \%$ narrowly ellipsoids, $9 \%$ spheroids, $8 \%$ narrowlly spheroids and $15 \%$ ellipsoid-pointed (Table 5 ). The average weight of 10 seeds per genotype ranged from 5 to $49.4 \mathrm{~g}$ with an overall average of $19.74 \mathrm{~g}$ (Table 2 ). The number of carpels varies from 2 to 4 carpels per seed in Agadir and Essaouira provinces and from 2 to 3 in Ait Baha and Sidi Ifni provinces.

In terms of seed shape, $47 \%$ of this argan population is composed of genotypes with oval seeds, $12 \%$ with round or spheroid seeds and $41 \%$ are fusiform (Figure 8 ).

\section{Search for potential descriptors for argan trees}

Analysis of variance: The results of the analyses of variance

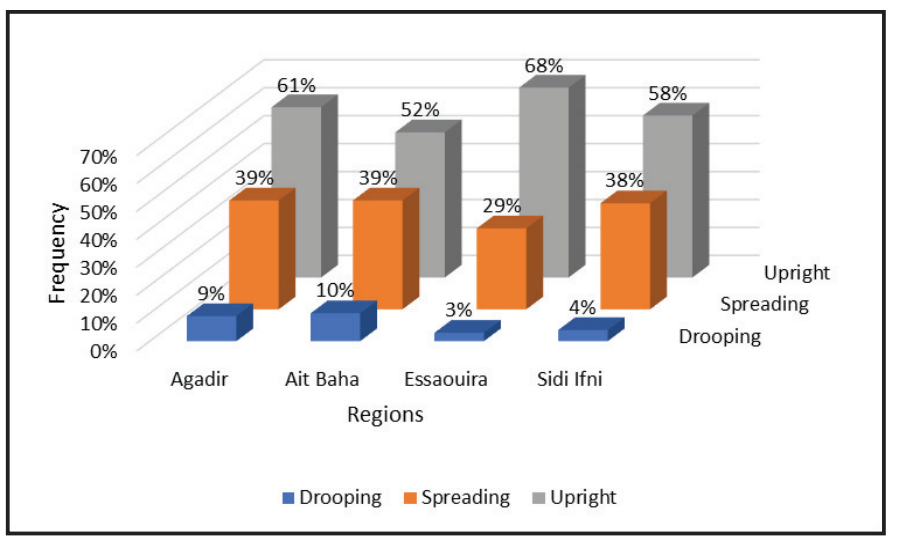

Figure 5: Frequency of growth habits of 255 argan trees sampled from four sites.

of 25 characteristics evaluated on the total sample of 255 trees showed different variations. The $\mathrm{F}$ values and the probability level make it possible to classify the characteristics in order of discrimination strength (Table 6). Very highly significant variations ( $\mathrm{P}$-values <0.0001) were found for the internode distance, fruit shape, leaf shape, leaf area, leaf shape, tree shape and leaf color, highly significant variations for the seed surface area, branch length, spine density and the seed shape. There was significant difference for growth habit, seed length, leaf base shape, fruit diameter and leaf length and no 
significant difference for the remaining characters (leaf apex shape, fruit length, seed weight, the seed perimeter, leaf width and fruit diameter/length ratio). Stepwise regression

Stepwise regression analyses show that all the qualitative characteristics explain up to $21 \%$ of the diversity. All quantitative characteristics explain about $33 \%$ of the total variability, with six variables (traits) accounting for $32 \%$. The combination of the two types of characteristics explains nearly

Table 4: Percentage of diversity of different characteristics of argan tree.in selected sites in the four provinces.

\begin{tabular}{|c|c|c|c|c|}
\hline Characteristics & Agadir (\%) & Ait Baha (\%) & Essaouira (\%) & Sidi Ifni (\%) \\
\hline Fruit diameter & 34.17 & 16.88 & 35.25 & 12.81 \\
\hline Fruit length & 31.75 & 23.51 & 32.41 & 11.64 \\
\hline Diameter/length ratio & 35.12 & 24.77 & 29.82 & 9.49 \\
\hline Leaf area & 26.29 & 18.16 & 23.57 & 28.78 \\
\hline Leaf length & 24.85 & 25.07 & 21.52 & 27.14 \\
\hline Leaf perimeter & 26.21 & 24.16 & 17.71 & 27.85 \\
\hline Number of carpels & 7.01 & 29.42 & 32.30 & 31.27 \\
\hline Weight of 10 grains & 29.98 & 20.06 & 33.68 & 16.27 \\
\hline Seed perimeter & 33.89 & 18.23 & 37.45 & 8.79 \\
\hline Seed area & 28.79 & 17.45 & 39.15 & 11.33 \\
\hline Seed length & 31.58 & 20.86 & 36.37 & 9.39 \\
\hline Seed diameter & 34.03 & 15.24 & 38.78 & 10.51 \\
\hline Spine length & 23.77 & 32.44 & 20.18 & 22.32 \\
\hline $\begin{array}{l}\text { Spine density on } 20 \mathrm{~cm} \\
\text { branch }\end{array}$ & 22.70 & 29.01 & 17.41 & 28.35 \\
\hline Tree height & 31.69 & 41.15 & 13.12 & 14.02 \\
\hline Number of trunks & 3.41 & 32.12 & 34.11 & 30.36 \\
\hline Internode distance & 28.64 & 27.22 & 27.17 & 16.97 \\
\hline Branch length & 32.56 & 19.54 & 24.55 & 16.28 \\
\hline Cover diameter & 34.39 & 22.45 & 21.56 & 21.59 \\
\hline Tree diameter & 20.27 & 44.05 & 22.17 & 13.50 \\
\hline
\end{tabular}

$42 \%$ of the total diversity in the sampled population (Figure 9). The first column of the table shows the order of selection of the characteristics or traits (Table 7). ' $\mathrm{T}$ ' stands for 'True' and shows which trait(s) is/are selected at the corresponding order. Based on the selection order and the value of Adjr ${ }^{2}$ we can select the most discriminating traits. Among the most discriminating characters, the elliptic leaf shape explains $3.3 \%$ of the total diversity, followed by the pointed ellipsoid fruit shape adding $2.3 \%$. Based on the same analysis, 21 qualitative traits explain $21.1 \%$ of the total diversity, the majority of which are related to fruit shape, leaf shape, leaf blade base and leaf color. Leaf apex shapes do not add any significant contribution to Adjr ${ }^{2}$. This result confirms that of the ANOVA (Tables 6,7).

\section{Discussion}

The descriptors provide crucial information that can help to ensure the efficient conservation and better use of genetic resources. This study aims to provide conservationists, gene bank curators, researchers, breeders, and other users with descriptors that can help in the characterization and monitoring of argan tree diversity. Out of the 31 characteristics studied, the height and diameter of the tree, the diameter of the crown (which are depending on the age and protection status of the tree) and the health status of the tree cannot be considered in the list of descriptors for the characterization of phenotypic diversity. Also, certain characteristics such as the number of grouped leaves and the length of old branches that remain highly variable within the same tree or affected by cutting and overgrazing should not be included among the characterization parameters. For some characteristics such as leaf persistence and alternating fruiting, observation should be made over several years. However, all these characteristics are important performance indicators.

The results obtained show the existence of great variability within the total population of the argan tree for most of the characteristics confirming the results obtained on the argan tree by other researchers [18-20]. This diversity may be due

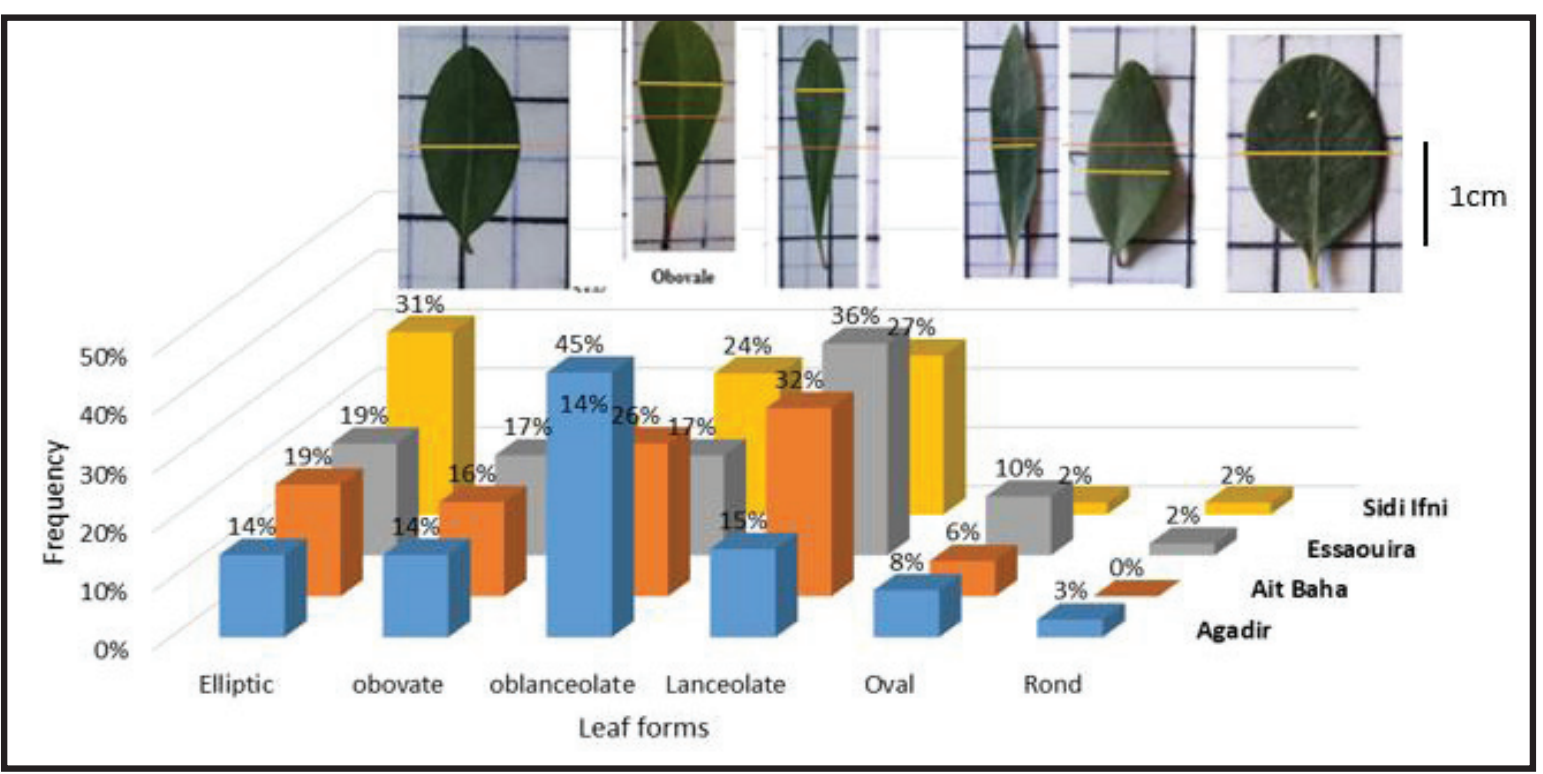

Figure 6: Frequency of various forms of leaves of argan trees in the four sites. 


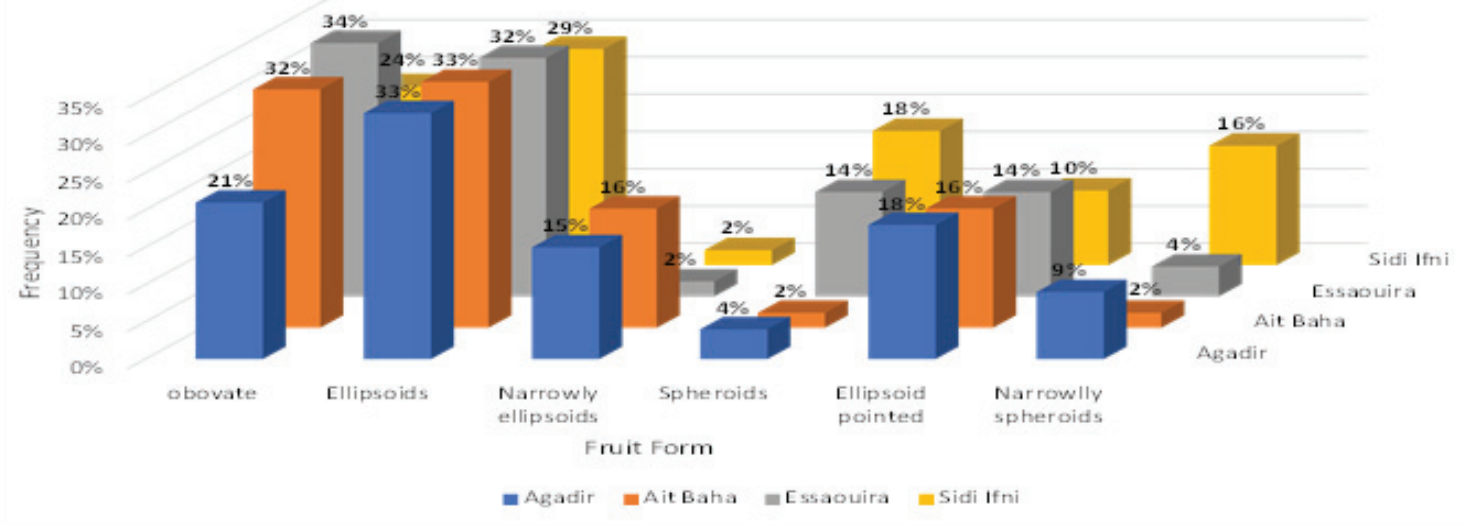

Figure 7: Frequency of various fruit forms of 215 argan trees sampled from the four provinces or Morocco.

Table 5: Frequencies of qualitative characteristics of argan trees in sites surveyed in the four provinces of Morocco.

\begin{tabular}{|c|c|c|c|c|c|c|}
\hline Characteristics & Groups & Agadir & Ait Baha & Essaouira & Sidi Ifni & Total frequency (\%) \\
\hline \multirow{5}{*}{ Tree form } & Type I & 8 & 4 & 10 & 11 & 13 \\
\hline & Type II & 23 & 14 & 17 & 17 & 28 \\
\hline & Type III & 14 & 20 & 16 & 11 & 24 \\
\hline & Type IV & 8 & 17 & 11 & 10 & 18 \\
\hline & Type V & 27 & 6 & 7 & 2 & 17 \\
\hline \multirow{6}{*}{ Leaf form } & Elliptic & 10 & 12 & 11 & 16 & 20 \\
\hline & Obovate & 10 & 10 & 10 & 7 & 15 \\
\hline & Oblanceolate & 32 & 16 & 10 & 12 & 29 \\
\hline & Lanceolate & 11 & 20 & 21 & 14 & 27 \\
\hline & Oval & 6 & 4 & 6 & 1 & 7 \\
\hline & Round & 2 & 0 & 1 & 1 & 2 \\
\hline \multirow{3}{*}{ Leaf base shape } & Obtus & 3 & 3 & 3 & 3 & 5 \\
\hline & Cuneate & 30 & 24 & 27 & 30 & 46 \\
\hline & Attenuate & 38 & 35 & 29 & 18 & 49 \\
\hline \multirow{4}{*}{ Leaf colour } & Green & 24 & 27 & 21 & 28 & 39 \\
\hline & Yellowish Green & 34 & 14 & 19 & 8 & 30 \\
\hline & Dark green & 16 & 11 & 15 & 8 & 20 \\
\hline & Light green & 7 & 9 & 6 & 7 & 11 \\
\hline \multirow{3}{*}{ Leaf apex shape } & Acute & 18 & 24 & 28 & 13 & 34 \\
\hline & Notched & 0 & 0 & 2 & 0 & 1 \\
\hline & Round & 53 & 38 & 29 & 38 & 65 \\
\hline \multirow{3}{*}{ Tree Growth habit } & Drooping & 7 & 6 & 2 & 2 & 7 \\
\hline & Spreading & 29 & 24 & 17 & 19 & 35 \\
\hline & Upright & 45 & 32 & 40 & 29 & 58 \\
\hline \multirow{2}{*}{ Growth stage } & Adult & 80 & 58 & 64 & 51 & 99 \\
\hline & Juvenile & 0 & 2 & 0 & 0 & 1 \\
\hline \multirow{6}{*}{ Fruit form } & Obovate & 140 & 182 & 170 & 120 & 27 \\
\hline & Ellipsoid & 220 & 190 & 162 & 140 & 32 \\
\hline & Narrowlly ellipsoid & 100 & 90 & 10 & 10 & 9 \\
\hline & Spheriod & 30 & 10 & 70 & 90 & 9 \\
\hline & Ellipsoid pointed & 120 & 90 & 70 & 50 & 15 \\
\hline & Narrowlly spheriod & 60 & 10 & 20 & 80 & 8 \\
\hline
\end{tabular}

Type I: Very thorny and very branched tree with very short branches, Type II: Thorny, branched with short branches; Type III: Very thorny, very branched with moderately long branches, Type IV: Thorny, less branched with long branches and Type V; very little thorns, slightly branched with very long branches.

to the species' allogamy and entomophilia nature, which maintain a high level of heterozygosity [21,22]. This diversity is also observed within each of the four provinces surveyed, but differences in averages are noted between regions for some measured traits reflecting differences in argan growing conditions. Indeed, the absence of young seedlings and the reduced number of juvenile plants could also affect the diversity of the argan tree and thus reduce its ability to ensure plasticity against climate change and biotic stresses. Similarly, the health status of trees shows the negative effects of lichens on trees in all provinces with more pronounced effects in Sidi Ifni province. 
Table 6: Results of ANOVA showing only the significant characteristics.

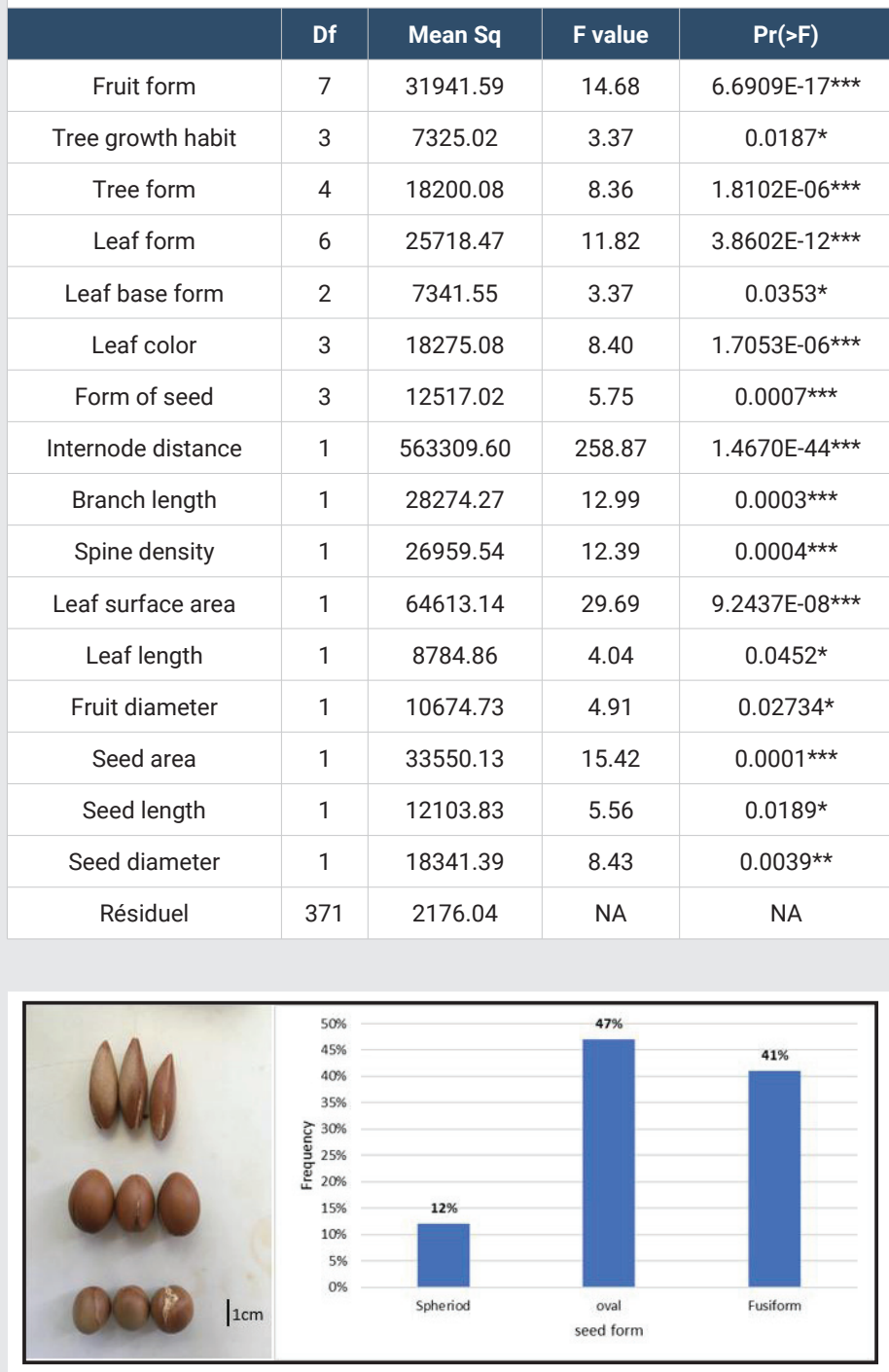

Figure 7: Different forms of seed of argan tree (7a) (button-up) and their respective frequencies $(7 \mathrm{~b})$ in the study zone.

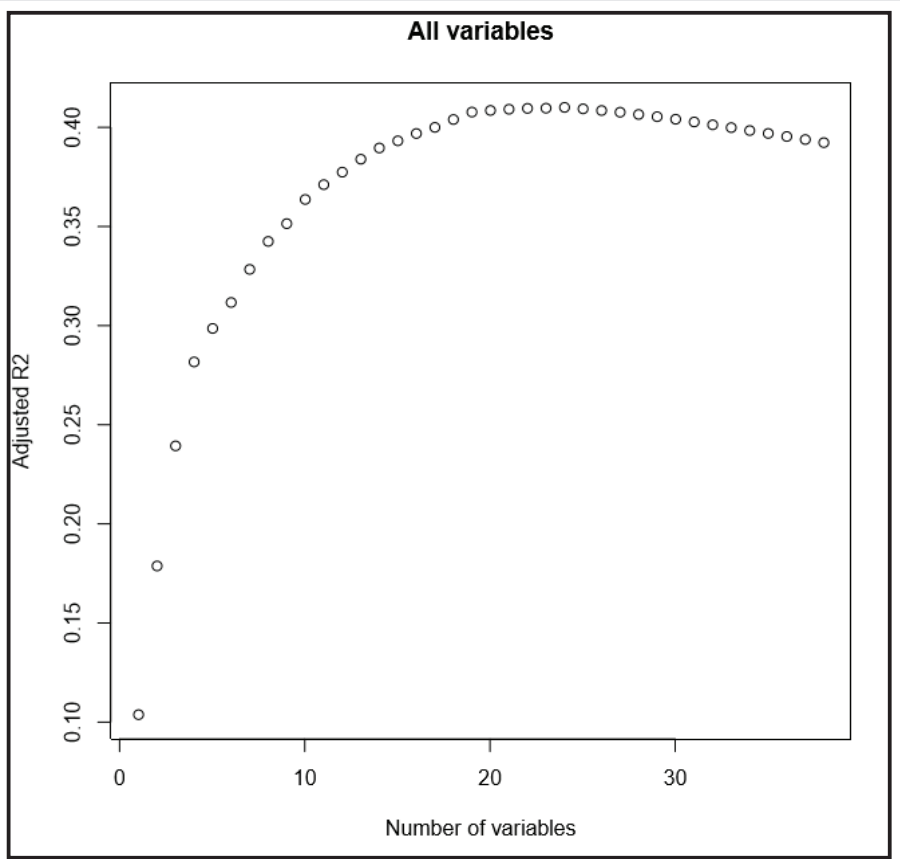

Figure 9: Regression model for both the qualitative and quantitative characteristics.
Frequency differences for qualitative traits are also observed between sites and can be attributed to sampling. These results are consistent with those obtained by Bellefontaine [23] for tree height, by Zahidi, et al, [1] and Metougui [7] for leaf shape and length, and by Msanda, et al. [24] for leaf colour. For the tree form, the difference in frequency between provinces is similar to the results of Zahidi, et al. [5], but the latter found the type IV to be predominant in Ait Baha. The range of the leaf size concord to the results of Metougui [12] but larger than those reported by Zahidi, et al. [1]. The weight and dimensions of fruits and seeds were similar to those reported in previous studies $[6,19,20]$. The seed shape is similar to the observations of Metougui [7] and Ait Aabd, et al. [25]. The number of carpels varied between 2 and 4 in this study while Aid Aabd, et al. [25] reported seeds with 1 and 5 carpels but are rare. All these differences can be attributed to the differences in the selected sites and the effect of sampling. Unlike previous researchers who use a combination of leaf base form and leaf apex form to name the various leaf forms [4], we proposed a more simpler naming approach based on the relative position of the longest leaf diameter and the central leaf diameter as illustrated by Krisch [11]. This new leaf naming approach will make it easier for identification and grouping or argan trees.

The results of the rcegression analysis (stepwise), showed that except for the internode distance, the quantitative descriptors allow a good discrimination of the argan trees and could consequently be used in the first place because of their ease in visual recognition. The most discriminating of these characteristics are the shape/form of the leaves and fruits, the color of the leaves, the leaf apex form, leaf base form and the color of leaves. These same descriptors were used for Vitellaria paradoxa a tree from sub-Saharan Africa that belongs to the same botanical family as the argan tree [26]. Visually in the field, the trees with very little thorns, slightly branched with very long branches are easily distinguished from the other types. For the other characters, the classification can vary from one person to another especially for the close classes within the same characteristic, therefore it is imperative to standardize the judgment of these characters.

Apart from biotic factors, environmental factors also shape the phenotype. All forms of the various descriptors are found in each region, however their frequencies are differing by region which could be explained by the differences in agroclimatic conditions. The results of the principal component analysis of the bioclimatic data of the study zone showed each region belongs to a distinct agroecological zone. The analysis of variance shows that there is a significant difference between descriptors for trees originated from different regions. For instance, the crown largest average diameter, highest average (5.6) and maximum number of trunks (17) per tree were recorded in Essaouira. This could be attributed partly to the fact that Essaouira has the highest annual precipitation among the four studied regions.

The results of this study show the rarity of individuals with the notched leaf apex shape, the obtuse shape of the base of the leaf, the round shape of the leaf and drooping form of trees. The category (Type V) of trees with very few thorns, few branches and very long branches is observed in all sites. 
Table 7: Contribution of different plant traits in the discrimination of the argan tree population diversity

\begin{tabular}{|c|c|c|c|c|c|c|c|c|c|c|c|c|c|c|c|c|c|c|c|c|c|c|c|c|c|c|c|c|c|}
\hline & FrF-E & $\begin{array}{l}\text { FrF- } \\
\text { Ep }\end{array}$ & $\begin{array}{c}\text { FrF- } \\
\text { es }\end{array}$ & $\begin{array}{l}\text { FrF- } \\
\text { eE }\end{array}$ & $\begin{array}{c}\text { FrF- } \\
\text { Ob }\end{array}$ & FrF-S & $\begin{array}{c}\text { FrF- } \\
\text { Sp }\end{array}$ & LfF-E & LfF-L & $\begin{array}{l}\text { LfF- } \\
\text { Obl }\end{array}$ & $\begin{array}{c}\text { LfF- } \\
\text { Ob }\end{array}$ & $\begin{array}{c}\text { LfF- } \\
\text { Ov }\end{array}$ & LfF-R & LaF-A & $\begin{array}{c}\text { LaF- } \\
\text { Ec }\end{array}$ & LaF-O & LaF-R & LbF-A & LbF-C & LbF-O & LfC-G & $\begin{array}{l}\text { LfC- } \\
\text { Dg }\end{array}$ & $\begin{array}{l}\text { LfC- } \\
\text { Lg }\end{array}$ & $\begin{array}{l}\text { LfC- } \\
\mathrm{Yg}\end{array}$ & SdF-F & SdF-O & SdF-S & $r^{2}$ & $\operatorname{Adj} r^{2}$ \\
\hline 1 & & & & & & & & $\mathrm{~T}$ & & & & & & & & & & & & & & & & & & & & 0.033 & 0.033 \\
\hline 2 & & $\mathrm{~T}$ & & & & & & $\mathrm{~T}$ & & & & & & & & & & & & & & & & & & & & 0.057 & 0.056 \\
\hline 3 & $T$ & $T$ & & & & & & $\mathrm{~T}$ & & & & & & & & & & & & & & & & & & & & 0.074 & 0.073 \\
\hline 4 & & & & & $\mathrm{~T}$ & & & $\mathrm{~T}$ & & & & T & & & & & & & & & & & & & T & & & 0.086 & 0.085 \\
\hline 5 & & & & & $\mathrm{~T}$ & & & $\mathrm{~T}$ & & & & $\mathrm{~T}$ & & & & & & & & $\mathrm{~T}$ & & & & & $\mathrm{~T}$ & & & 0.104 & 0.102 \\
\hline 6 & & & & & $\mathrm{~T}$ & & & & T & & & & & & & & & T & T & $\mathrm{T}$ & & & & & $\mathrm{T}$ & & & 0.118 & 0.116 \\
\hline 7 & $\mathrm{~T}$ & $\mathrm{~T}$ & & & & & & & $\mathrm{~T}$ & & & & & & & & & $\mathrm{~T}$ & $\mathrm{~T}$ & $\mathrm{~T}$ & & & & & $\mathrm{~T}$ & & & 0.129 & 0.126 \\
\hline 8 & $\mathrm{~T}$ & $\mathrm{~T}$ & & & & & & & $\mathrm{~T}$ & & & & & & & & & $\mathrm{~T}$ & $\mathrm{~T}$ & $\mathrm{~T}$ & & T & & & $\mathrm{T}$ & & & 0.141 & 0.138 \\
\hline 9 & & & & & $\mathrm{~T}$ & & & & $\mathrm{~T}$ & & & & & & & & & $\mathrm{~T}$ & $\mathrm{~T}$ & $\mathrm{~T}$ & $\mathrm{~T}$ & $\mathrm{~T}$ & $\mathrm{~T}$ & & $\mathrm{~T}$ & & & 0.150 & 0.147 \\
\hline 10 & $\mathrm{~T}$ & $\mathrm{~T}$ & & & & & & & $\mathrm{~T}$ & & & & & & & & & $\mathrm{~T}$ & T & T & $\mathrm{T}$ & T & $\mathrm{T}$ & & $\mathrm{T}$ & & & 0.167 & 0.163 \\
\hline 11 & T & $\mathrm{T}$ & & & & $\mathrm{T}$ & & & $\mathrm{T}$ & & & & & & & & & $\mathrm{T}$ & $\mathrm{T}$ & $\mathrm{T}$ & $\mathrm{T}$ & $\mathrm{T}$ & $\mathrm{T}$ & & $\mathrm{T}$ & & & 0.172 & 0.168 \\
\hline 12 & T & $\mathrm{T}$ & $\mathrm{T}$ & & & $\mathrm{T}$ & & & $\mathrm{T}$ & & & & & & & & & $\mathrm{T}$ & $\mathrm{T}$ & $\mathrm{T}$ & $\mathrm{T}$ & $\mathrm{T}$ & $\mathrm{T}$ & & $\mathrm{T}$ & & & 0.180 & 0.176 \\
\hline 13 & $\mathrm{~T}$ & $\mathrm{~T}$ & $\mathrm{~T}$ & & & $\mathrm{~T}$ & & & $\mathrm{~T}$ & & & & $\mathrm{~T}$ & & & & & $\mathrm{~T}$ & $\mathrm{~T}$ & $\mathrm{~T}$ & $\mathrm{~T}$ & $\mathrm{~T}$ & $\mathrm{~T}$ & & $\mathrm{~T}$ & & & 0.187 & 0.182 \\
\hline 14 & $\mathrm{~T}$ & $\mathrm{~T}$ & $\mathrm{~T}$ & & & $\mathrm{~T}$ & $\mathrm{~T}$ & & $\mathrm{~T}$ & & & & & & & & & $\mathrm{~T}$ & $\mathrm{~T}$ & $\mathrm{~T}$ & $\mathrm{~T}$ & $\mathrm{~T}$ & $\mathrm{~T}$ & & $\mathrm{~T}$ & $\mathrm{~T}$ & & 0.191 & 0.187 \\
\hline 15 & T & $\mathrm{T}$ & $\mathrm{T}$ & $\mathrm{T}$ & T & $\mathrm{T}$ & $\mathrm{T}$ & & T & & & & & & & & & $\mathrm{T}$ & $\mathrm{T}$ & T & $\mathrm{T}$ & $\mathrm{T}$ & $\mathrm{T}$ & & T & & & 0.200 & 0.194 \\
\hline 16 & $\mathrm{~T}$ & $\mathrm{~T}$ & $\mathrm{~T}$ & $\mathrm{~T}$ & $\mathrm{~T}$ & $\mathrm{~T}$ & $\mathrm{~T}$ & & $\mathrm{~T}$ & & & & T & & & & & T & $\mathrm{T}$ & $\mathrm{T}$ & T & $\mathrm{T}$ & $\mathrm{T}$ & & $\mathrm{T}$ & & & 0.206 & 0.200 \\
\hline 17 & $\mathrm{~T}$ & $\mathrm{~T}$ & $\mathrm{~T}$ & $\mathrm{~T}$ & $\mathrm{~T}$ & $\mathrm{~T}$ & $\mathrm{~T}$ & & $\mathrm{~T}$ & & & & $\mathrm{~T}$ & & & & & T & $\mathrm{T}$ & T & $\mathrm{T}$ & $\mathrm{T}$ & $\mathrm{T}$ & $\mathrm{T}$ & $\mathrm{T}$ & & & 0.210 & 0.204 \\
\hline 18 & $\mathrm{~T}$ & $\mathrm{~T}$ & $\mathrm{~T}$ & $\mathrm{~T}$ & $\mathrm{~T}$ & $\mathrm{~T}$ & $\mathrm{~T}$ & $\mathrm{~T}$ & $\mathrm{~T}$ & & & & $\mathrm{~T}$ & & & & & $\mathrm{~T}$ & T & T & $\mathrm{T}$ & $\mathrm{T}$ & $\mathrm{T}$ & $\mathrm{T}$ & $\mathrm{T}$ & & & 0.213 & 0.206 \\
\hline 19 & $\mathrm{~T}$ & $\mathrm{~T}$ & $\mathrm{~T}$ & $\mathrm{~T}$ & $\mathrm{~T}$ & $\mathrm{~T}$ & $\mathrm{~T}$ & $\mathrm{~T}$ & $\mathrm{~T}$ & & & $\mathrm{~T}$ & $\mathrm{~T}$ & & & & & $\mathrm{~T}$ & $\mathrm{~T}$ & $\mathrm{~T}$ & $\mathrm{~T}$ & $\mathrm{~T}$ & $\mathrm{~T}$ & $\mathrm{~T}$ & $\mathrm{~T}$ & & & 0.215 & 0.209 \\
\hline 20 & $\mathrm{~T}$ & $\mathrm{~T}$ & $\mathrm{~T}$ & $\mathrm{~T}$ & $\mathrm{~T}$ & $\mathrm{~T}$ & $\mathrm{~T}$ & $\mathrm{~T}$ & $\mathrm{~T}$ & & & $\mathrm{~T}$ & $\mathrm{~T}$ & & & $\mathrm{~T}$ & & $\mathrm{~T}$ & $\mathrm{~T}$ & $\mathrm{~T}$ & $\mathrm{~T}$ & $\mathrm{~T}$ & $\mathrm{~T}$ & $\mathrm{~T}$ & $\mathrm{~T}$ & & & 0.217 & 0.210 \\
\hline 21 & $\mathrm{~T}$ & $\mathrm{~T}$ & $\mathrm{~T}$ & $\mathrm{~T}$ & $\mathrm{~T}$ & $\mathrm{~T}$ & $\mathrm{~T}$ & $\mathrm{~T}$ & $\mathrm{~T}$ & & & $\mathrm{~T}$ & T & & & $\mathrm{T}$ & & $\mathrm{T}$ & $\mathrm{T}$ & $\mathrm{T}$ & $\mathrm{T}$ & $\mathrm{T}$ & $\mathrm{T}$ & $\mathrm{T}$ & $\mathrm{T}$ & $\mathrm{T}$ & & 0.218 & 0.211 \\
\hline 22 & $\mathrm{~T}$ & $\mathrm{~T}$ & $\mathrm{~T}$ & $\mathrm{~T}$ & T & $\mathrm{T}$ & $\mathrm{T}$ & $\mathrm{T}$ & $\mathrm{T}$ & & & $\mathrm{T}$ & T & & & T & T & T & T & $\mathrm{T}$ & $\mathrm{T}$ & T & $\mathrm{T}$ & T & $\mathrm{T}$ & $\mathrm{T}$ & & 0.219 & 0.211 \\
\hline 23 & $\mathrm{~T}$ & $\mathrm{~T}$ & $\mathrm{~T}$ & $\mathrm{~T}$ & $\mathrm{~T}$ & $\mathrm{~T}$ & $\mathrm{~T}$ & T & $\mathrm{T}$ & & & $\mathrm{T}$ & T & & & $\mathrm{T}$ & T & $\mathrm{T}$ & T & T & $\mathrm{T}$ & $\mathrm{T}$ & $\mathrm{T}$ & $\mathrm{T}$ & $\mathrm{T}$ & $\mathrm{T}$ & $\mathrm{T}$ & 0.219 & 0.211 \\
\hline 24 & $\mathrm{~T}$ & $\mathrm{~T}$ & $\mathrm{~T}$ & $\mathrm{~T}$ & $\mathrm{~T}$ & $\mathrm{~T}$ & $\mathrm{~T}$ & $\mathrm{~T}$ & $\mathrm{~T}$ & $\mathrm{~T}$ & $\mathrm{~T}$ & T & $\mathrm{T}$ & & & $\mathrm{T}$ & $\mathrm{T}$ & & $\mathrm{T}$ & $\mathrm{T}$ & $\mathrm{T}$ & $\mathrm{T}$ & $\mathrm{T}$ & $\mathrm{T}$ & $\mathrm{T}$ & $\mathrm{T}$ & $\mathrm{T}$ & 0.219 & 0.211 \\
\hline 25 & $\mathrm{~T}$ & $\mathrm{~T}$ & T & $\mathrm{T}$ & $\mathrm{T}$ & $\mathrm{T}$ & $\mathrm{T}$ & $\mathrm{T}$ & $\mathrm{T}$ & $\mathrm{T}$ & $\mathrm{T}$ & $\mathrm{T}$ & $\mathrm{T}$ & $\mathrm{T}$ & $\mathrm{T}$ & T & & $\mathrm{T}$ & $\mathrm{T}$ & & $\mathrm{T}$ & $\mathrm{T}$ & $\mathrm{T}$ & $\mathrm{T}$ & $\mathrm{T}$ & $\mathrm{T}$ & $\mathrm{T}$ & 0.219 & 0.210 \\
\hline
\end{tabular}

FrF-E; Fruit form ellipsoid, FrF-Ep; Fruit form Ellipsoid pointed, FrF-O; Fruit form obovate, FrF-S; Fruit form spheroid, FrF-eE; Fruit form narrowlly ellipsoid, FrF-Sp; Fruit form spheriod pointed, LfF-E; ,LfF-L; Leaf form lanceolate, LfF-Ob; Leaf form obovate, LfF-Ov; Leaf form oval, LfF-Obl; Leaf form oblanceolate, LfF-R; Leaf form round, LaF-R; Leaf apex form round, LaF-A; Leaf apex, form acute/attenuate, LaF-O; Leaf apex form obtuse, LbF-A; Leaf base form attenuate, LaF-EC; Leaf apex form notched, LbF-C; Leaf base form cunéiforme, LbF-O; Leaf base form obtuse, LfC-G; Leaf colour green, LfC-Lg; Leaf colour light green, $L f C$-Yg; Leaf colour yellowish green, LfC-Dg; Leaf colour dark green, SdF-F; Seed form fusiform, SdF-O; Seed form Oval, SdF-S; Seed form Spheroid, Adj ${ }^{2}$; Adjusted R square

\section{Conclusion}

This study shows there is high phenotypic diversity of the argan tree in all the provinces surveyed and is an important contribution towards the development of descriptors for the characterization of the argan tree. Qualitative descriptors must be combined with the observed quantitative characteristics to explain a large part of genetic diversity. These descriptors can also be used in combination with production, quality and tolerance characteristics and resistance to abiotic and abiotic stresses for the selection and protection of clones that can be used in the promotion of arganiculture. The descriptors can also help in demarcating provinces with greater phenotypic diversity to promote efficient in situ conservation of different ecosystems in the argan forest. In view of these results, we recommend de completion of this work by molecular characterization in order to clearly elucidate the genetic structure of the argan tree and better understand the genetic differences of the studied population. The molecular tool can also be used to search for markers associated with different characters.

\section{Acknowledgement}

This study is part of the efforts of the National Agency for the Development of Oases Areas and Argan Zones (ANDZOA) National Argan Centre supported by the financial contribution of GIZ "Deutsche Gesellschaft fur Internationale Zusammenarbeit (GIZ) GmbH" and the technical contribution of International Center for Agriculture Research in Dry Areas (ICARDA) and Institut Agronomique et Vétérinaire Hassan II.

\section{References}

1. Zahidi A, Bani-Aameur F, El Mousadik A (2013) Seasonal change effects on phenology of Argania spinosa (L.) in the fields. Journal of Ecology and the Natural Environment 5: 189-205. Link: https://bit.ly/2To4vcX

2. Aziki S (2002) L'arganeraie du Sud-Ouest marocain: Développement durable et participation dans un système agro sylvo pastoral en voie de dégradation. Thèse de Doctorat, Université Libre de Bruxelles ULB, 239. Link: https://bit.ly/3zmfFiS

3. Bouzoubaa Z (2006) Etude la variabilité et du comportement de la tolérance aux stress abiotiques chez Argania spinosa L. Skeels. Thèse Univ Ibn Zohr Fac Sci Agadir. 
4. Zahidi A, Bani-Aameur F, Dupuis $P$ (1995) Caractérisation de la ramification de l'arganier. Actes du Colloque International: La Forêt Face à la Désertification: Cas des Arganeraies. Faculté des Sciences d'Agadir 36-52.

5. Zahidi A, Bani-Aameur F, El Mousadik A (2014) Shapes of argan (Argania spinosa (L.) Skeels) in field classified on the basis of branching and growth characters. Int J Pure App Biosci 2: 27-37. Link: https://bit.ly/3cA9AWy

6. Bani-Aameur F (2004) Morphological diversity of argan (Argania spinosa (L.) Skeels) populations in Morocco. Forest Genetics 11: 311-316. Link: https://bit.ly/2TZpeEv

7. Metougui ML, Mokhtari M, Maughan PJ, Jellen EN, Benlhabib O (2017) Morphological Variability, Heritability and Correlation Studies within an Argan Tree Population (Argania spinosa (L.) Skeels) Preserved in situ. International Journal of Agriculture and Forestry 7: 42-51. Link: https://bit.ly/3gqTqjh

8. Bani-Aameur F, Ferradous A, Dupuis P (1999) Typology of Argania spinosa (Sapotaceae) fruits and stones. Forest Genetics 6: 213-219. Link: https://bit.ly/3gp0i0A

9. Dallmeier F (1992) Long-term Monitoring of biological Diversity in Tropica forest Areas: methods for Establishment and Inventory of permanent plots. M.A.B. Digest 11. United Nations Educational, Scie. And Cultural Organization (UNESCO). Paris. France. 72. Link: https://bit.ly/3wiHFIJ

10. UPOV (2015) international union for the protection of new varieties of plants, TWF/46/26 Add pg 6, Geneva.

11. Krisch P (n.d.) (2019) Identify Australian Native Tree Species by Leaf Characteristics. Tree Identification Pictures. Link: https://bit.ly/3vhuVKK

12. Louay MM (2018) Etude de la variabilité génétique et contribution à la domestication de l'arganier (Argania spinosa L. skeels), Thèse Doctorale, IAV Hassan II.

13. Sainte-Laguë A (1910) La représentation proportionnelle et la méthode des moindres carrés Annales scientifiques de l'É.N.S. 529-542. Link: https://bit.ly/3zcAM7k

14. Bates $D$, Maechler $M$, Bolker $B$, Walker $S$ (2015) Montage de modèles à effets mixtes linéaires à l'aide de Ime4. Journal of Statistical Software 67: 1-48.

15. Hirotugu A (1973) Théorie de l'information et extension du principe de maximum de vraisemblance, dans Deuxième symposium international sur la théorie de l'information 267-281.

16. Lumley Thomas basé sur le code Fortran d'Alan Miller (2017) sauts Sélection du sous-ensemble de régression. $\mathrm{R}$ package version 3.0. Link: https://bit.ly/3ziDpEB

17. Fick SE, Hijmans RJ (2017) WorldClim 2: new $1 \mathrm{~km}$ spatial resolution climate surfaces for global land areas. International Journal of Climatology 37: 4302 4315. Link: https://bit.ly/3zcAQE6

18. Ait Aabd N, El Ayadi F, Msanda F, El Mousadik A (2010) Genetic variability of argan tree and preselection of the candidate plus trees. Notulae Botanicae Horti Agrobotanici Cluj-Napoca 38: 293-301. Link: https://bit.ly/3vgAbOR

19. Ait Aabd N, Msanda F, El Mousadik A (2012) Univariate and multivariate analysis of agronomical traits of preselected argan trees. Notulae Botanicae Horti Agrobotanici Cluj-Napoca 40: 308-316. Link: https://bit.ly/2SkSDsm

20. Bani-Aameur F, Ferradous A (2001) Fruits and stone variability in three argan (Argania spinosa (L.) Skeels) populations. Forest Genetics 8: 39-43. Link: https://bit.ly/3ivoQI5

21. Benlahbil S, Zahidi A, Bani-Aameur F, El Mousadik A (2015) Duration of Blossoming, Longevity of Argan Flower and Assessment of Pollen Fertility by Staining. International Journal of Agriculture and Forestry 5: 291-304. Link: https://bit.ly/3xfkokU

22. Nerd A, Irijimovich V, Mizrahi Y (1998) Phenology, breeding system and fruit development of argan (Argania spinosa, Sapotaceae) cultivated in Israel. Econ Botany 52: 161-167. Link: https://bit.ly/3gfa0nC

23. Bellefontaine R (2010) De la domestication à l'amélioration variétale de l'arganier (Argania spinosa (L.) Skeels. Science et Changements Planetaires Secheresse 21: 42-53. Link: https://bit.ly/3zhniqV

24. Msanda F, El Aboudi A, Peltier J (2005) Biodiversité et biogéographie de l'arganeraie marocain. Cahiers Agricultures 14: 357-364. Link: https://bit.ly/3vff7ro

25. Ait Aabd N (2013) Apport des marqueurs phénotypiques et moléculaires pour l'analyse de la variabilité génétique de l'arganier Présélection pour le rendement en huile, Thèse Doctorale de l'Université Ibn Zohr. Agadir Morocco.

26. IPGRI INIA (2006) Descriptors for Shea tree (Vitellaria paradoxa). International Plant Genetic Resources Institute, Rome, Italy; Instituto Nacional de Investigación y Tecnología Agrariay Alimentaria, Madrid, Spain. Link: https://bit.ly/3pGAKjX

\section{Discover a bigger Impact and Visibility of your article publication with}

\section{Peertechz Publications}

\section{Highlights}

* Signatory publisher of ORCID

* Signatory Publisher of DORA (San Francisco Declaration on Research Assessment)

* Articles archived in worlds' renowned service providers such as Portico, CNKI, AGRIS, TDNet, Base (Bielefeld University Library), CrossRef, Scilit, J-Gate etc.

* Journals indexed in ICMJE, SHERPA/ROMEO, Google Scholar etc.

* OAI-PMH (Open Archives Initiative Protocol for Metadata Harvesting)

* Dedicated Editorial Board for every journal

* Accurate and rapid peer-review process

* Increased citations of published articles through promotions

* Reduced timeline for article publication

Submit your articles and experience a new surge in publication services (https://www.peertechz.com/submission).

Copyright: (C) 2021 Buernor AB, et al. This is an open-access article distributed under the terms of the Creative Commons Attribution License, which permits unrestricted use, distribution, and reproduction in any medium, provided the original author and source are credited.

Citation: Buernor AB, Amri A, Birouk A, Analy C, Kehel Z, et al. (2021) Contribution to the identification of morphological descriptors for the genetic diversity of argan tree (Argania spinosa L. Skeels). Glob J Ecol 6(1): 051-061. DOI: https://dx.doi.org/10.17352/gje.0000144 